\title{
Creatinine clearance and adverse hospital outcomes in patients with acute coronary syndromes: findings from the global registry of acute coronary events (GRACE)
}

\author{
J J Santopinto, K A A Fox, R J Goldberg, A Budaj, G Piñero, A Avezum, D Gulba, \\ J Esteban, J M Gore, J Johnson, E P Gurfinkel, on behalf of the GRACE Investigators*
}

See end of article for authors' affiliations

*See appendix for complete list of investigators and institutions.

\section{Correspondence to:}

Dr J J Santopinto, Intensive

Care Unit, Hospital

Municipal de Bahia

Blanca, Estomba 968

(8000) Bahia Blanca,

Provincia de Buenos Aires, Argentina;

jsantopinto@infovia.com.ar

Accepted 8 May 2003

\begin{abstract}
Objective: To determine whether creatinine clearance at the time of hospital admission is an independent predictor of hospital mortality and adverse outcomes in patients with acute coronary syndromes (ACS).

Design: A prospective multicentre observational study, GRACE (global registry of acute coronary events), of patients with the full spectrum of ACS.

Setting: Ninety four hospitals of varying size and capability in 14 countries across four continents.

Patients: 11774 patients hospitalised with ACS, including ST and non-ST segment elevation acute myocardial infarction and unstable angina.

Main outcome measures: Demographic and clinical characteristics, medication use, and in-hospital outcomes were compared for patients with creatinine clearance rates of $>60 \mathrm{ml} / \mathrm{min}$ (normal and minimally impaired renal function), $30-60 \mathrm{ml} / \mathrm{min}$ (moderate renal dysfunction), and $<30 \mathrm{ml} / \mathrm{min}$ (severe renal dysfunction).

Results: Patients with moderate or severe renal dysfunction were older, were more likely to be women, and presented to participating hospitals with more comorbidities than those with normal or minimally impaired renal function. In comparison with patients with normal or minimally impaired renal function, patients with moderate renal dysfunction were twice as likely to die lodds ratio $2.09,95 \%$ confidence interval 1.55 to 2.81 ) and those with severe renal dysfunction almost four times more likely to die (odds ratio $3.71,95 \%$ confidence interval 2.57 to 5.37 ) after adjustment for other potentially confounding variables. The risk of major bleeding episodes increased as renal function worsened.

Conclusion: In patients with ACS, creatinine clearance is an important independent predictor of hospital death and major bleeding. These data reinforce the importance of increased surveillance efforts and use of targeted intervention strategies in patients with acute coronary disease complicated by renal dysfunction.
\end{abstract}

$\mathrm{R}$ enal function, as measured by serum creatinine, blood urea nitrogen, or estimated creatinine clearance, has been shown in epidemiological studies and clinical trials to be an independent predictor of survival..$^{1-5}$ However, the prognostic significance of mild to moderate renal dysfunction in patients with acute coronary syndromes (ACS) without ST segment elevation is unknown. Mild renal impairment is associated with an increased risk of coronary artery disease and stroke, suggesting that cardiovascular disease may develop early in the course of renal dysfunction. ${ }^{6}$ Increased serum creatinine concentrations may reflect generalised vascular disease denoting early nephrovasculopathy in association with established atherosclerotic risk factors. ${ }^{5} 78$

The objective of the present study was to evaluate the prognostic impact of creatinine clearance on hospital mortality and adverse outcomes in a large and broad spectrum of patients with ACS. GRACE (global registry of acute coronary events) is a prospective multinational registry that includes the full spectrum of patients with ACS.

\section{METHODS}

Full details of the GRACE rationale and methods have been published..$^{9-11}$ The GRACE sample of patients is designed to reflect an unbiased population of patients with ACS, irrespective of geographical region. Ninety four hospitals located in 14 countries (Argentina, Australia, Austria, Belgium, Brazil, Canada, France, Germany, Italy, New Zealand, Poland, Spain, UK, USA) are participating in this observational study.
Patients entered in the registry had to be at least 18 years old and alive at the time of hospital presentation, to have been admitted for ACS as a presumptive diagnosis (that is, have symptoms consistent with acute ischaemia), and to have at least one of the following: electrocardiographic changes consistent with ACS, serial increases in serum biochemical markers of cardiac necrosis, and documentation of coronary artery disease. The qualifying ACS must not have been precipitated or accompanied by a significant comorbidity, trauma, or surgery. Where required, study investigators received approval to conduct the study from their local hospital ethics or institutional review board.

Data were collected at each site by a trained coordinator using a standardised case report form. Demographic characteristics, medical history, presenting symptoms, duration of prehospital delay, biochemical and electrocardiographic findings, treatment practices, and a variety of hospital outcome data were collected. Standardised definitions of all patient related variables, clinical diagnoses, and hospital complications and outcomes were used. ${ }^{11}$

Abbreviations: $A C E$, angiotensin converting enzyme; $A C S$, acute coronary syndromes; GRACE, global registry of acute coronary events; NSTEMI, non-ST segment elevation myocardial infarction; STEMI, ST segment elevation myocardial infarction; TRACE, trandolapril cardiac evaluation; $U A$, unstable angina 


\section{Description of study population}

The study sample consisted of patients with an admission diagnosis of ACS (primary admission diagnosis of myocardial infarction, unstable angina (UA), rule out myocardial infarction, or chest pain) for whom creatinine clearance data were available. Patients with an admission, as opposed to a discharge, diagnosis of ACS were chosen for analysis, as their treatment would have been based on this diagnosis. Degree of renal function was stratified according to stages of renal dysfunction adapted from the National Kidney Foundation recommendations. ${ }^{12}$ Serum creatinine is commonly used to estimate creatinine clearance but is a poor predictor of glomerular filtration rate. Glomerular filtration rate is the ideal for determining kidney function but it is difficult to measure. For practical purposes, estimated creatinine clearance is used as a correlate of glomerular filtration rate and is commonly estimated by using the Cockcroft-Gault formula without the need for 24 hour urine collection. ${ }^{12-14}$ Other formulas have been developed to estimate creatinine clearance rates in specific populations but these equations are more complex and may be limited in their application. ${ }^{15}$

Baseline serum creatinine and creatinine clearance rates (estimated by the Cockcroft-Gault formula ${ }^{14}$ ) were available for 11774 patients with ACS. Patients were divided into three groups according to their creatinine clearance rates: $>60 \mathrm{ml} /$ min or normal renal function (including patients with minimally impaired renal function; $\mathrm{n}=7591) ; 30-60 \mathrm{ml} / \mathrm{min}$ or moderate renal dysfunction $(\mathrm{n}=3397)$; and $<30 \mathrm{ml} / \mathrm{min}$ or severe renal dysfunction $(\mathrm{n}=786)$. The study sample was further divided into two subgroups of patients with ST segment elevation myocardial infarction (STEMI) and non-ST segment elevation myocardial infarction/UA (NSTEMI/UA). Patients with ST segment elevation or left bundle branch block on their admission ECG were defined as having STEMI, while the remaining patients were categorised as having NSTEMI/ UA. Patients presenting with cardiac arrest or in Killip class IV at the time of hospital admission were excluded from the present sample.

\section{Data analysis}

Demographic and clinical characteristics and incidence of adverse hospital outcomes were compared across the creatinine clearance groups for all ACS patients and separately within the STEMI and NSTEMI/UA subgroups. Differences in categorical variables between respective comparison groups were analysed using the $\chi^{2}$ test. The Kruskal-Wallis test was used to analyse differences in continuous variables. The association between creatinine clearance and adverse hospital outcomes (mortality, stroke, and major bleeding) were examined using univariate and multivariate logistic regression models. The following variables were included in stepwise regression analyses because of their relation with adverse hospital outcome ${ }^{16}$ : age, history of hypertension, diabetes, presenting heart rate, presenting systolic blood pressure, Killip class, positive initial cardiac enzymes (creatine kinase, creatine kinase MB, or troponin), ST segment deviation, anterior ST segment elevation, anterior ST segment depression, and significant Q wave, left bundle branch block, and other initial electrocardiographic changes (composite variable including atrioventricular block, ventricular paced rhythm, atrial fibrillation or flutter, right ventricle infarction, posterior infarction, and left ventricular hypertrophy). Subsequent stepwise models included the following variables, in addition to those listed above, to control for potentially confounding effects: sex, current smoker, medical history variables (myocardial infarction, congestive heart failure, peripheral arterial disease, atrial fibrillation, stroke, percutaneous coronary intervention, and coronary artery bypass grafting), and in-hospital treatments (percutaneous coronary intervention, coronary artery bypass grafting, thrombolytics, glycoprotein
IIb/IIIa, low molecular weight heparin, unfractionated heparin, aspirin, ticlopidine, or clopidogrel). Final regression models included independent predictors of the three principal hospital outcomes at $\alpha<0.05$. Crude and multivariable adjusted odds ratios, with accompanying 95\% confidence intervals, were reported for the respective creatinine clearance categories, in comparison with the referent group of patients with creatinine clearance $>60 \mathrm{ml} / \mathrm{min}$ (normal renal function).

\section{RESULTS}

The study sample consisted of 11774 patients with ACS whose serum creatinine concentrations were available at the time of hospital admission.

\section{Sample characteristics}

Table 1 shows baseline characteristics of patients with a diagnosis of ACS at the time of hospital admission according to extent of renal dysfunction. Patients with moderate or severe renal dysfunction were significantly older, were more likely to be women, and had a greater prevalence of previous myocardial infarction, diabetes, congestive heart failure, hypertension, peripheral vascular disease, atrial fibrillation, transient ischaemic attack or stroke, and prior coronary artery bypass grafting. Electrocardiographic changes (ST segment elevation, ST segment depression, or T wave inversion) were observed more frequently as the degree of renal dysfunction worsened. In patients with STEMI, electrocardiographic changes were seen less often as renal impairment increased.

\section{Practice patterns}

Overall, before hospital admission, patients with a diagnosis of ACS who had moderate or severe renal dysfunction were more likely to be treated with antiplatelet agents, angiotensin converting enzyme (ACE) inhibitors, $\beta$ blockers, angiotensin receptor blockers, and diuretics than patients with normal or minimally impaired renal function (table 2). These trends persisted in our two primary ACS comparison groups. During the index hospitalisation, patients with ACS who had moderate or severe renal dysfunction were less likely to be treated with antiplatelet agents, $\beta$ blockers, statins, and glycoprotein IIb/IIIa inhibitors across all ACS subgroups. Diuretics were more often prescribed to patients with renal dysfunction. ACE inhibitors were more likely to be prescribed to patients with a moderate degree of renal dysfunction, especially those with STEMI. Use of angiotensin receptor blockers increased as renal function worsened in patients in the NSTEMI/UA subgroup (table 2).

\section{Hospital outcomes}

In comparison with patients with normal or minimally impaired renal function, in both crude and multivariable adjusted analyses, patients with moderate and severe renal dysfunction were at significantly increased risk of hospital mortality and major bleeding episodes, but not of stroke (fig 1). Subsequent multivariate models adjusting for additional confounders yielded similar results. For patients with moderate renal dysfunction, the risk of hospital death was almost twofold greater. For patients with severe renal dysfunction, the risk of hospital death was nearly four times greater than for patients with normal renal function (fig 1). The risk of major bleeding episodes increased as renal function worsened (table 3). Trends of a greater risk of stroke were noted as renal function worsened throughout all ACS types though the point estimates of risk were not significant (table 3).

\section{DISCUSSION}

The prognosis and outcomes in patients with ACS have been well established by the results of randomised clinical trials. However, "real life" unselected patient populations have been 
Table 1 Baseline characteristics and clinical presentations of the study population

\begin{tabular}{|c|c|c|c|c|c|c|c|c|c|}
\hline \multirow[b]{2}{*}{ Renal function } & \multicolumn{3}{|l|}{ ACS } & \multicolumn{3}{|l|}{ STEMI } & \multicolumn{3}{|l|}{ NSTEMI/UA } \\
\hline & $\begin{array}{l}\text { Severe } \\
\text { dysfunction } \\
(n=786)\end{array}$ & $\begin{array}{l}\text { Moderate } \\
\text { dysfunction } \\
\text { (n=3397) }\end{array}$ & $\begin{array}{l}\text { Normal/ } \\
\text { minimally } \\
\text { impaired } \\
\text { ( } \mathrm{n}=7591)\end{array}$ & $\begin{array}{l}\text { Severe } \\
\text { dysfunction } \\
(n=301)\end{array}$ & $\begin{array}{l}\text { Moderate } \\
\text { dysfunction } \\
\text { ( } n=1347)\end{array}$ & $\begin{array}{l}\text { Normal/ } \\
\text { minimally } \\
\text { impaired } \\
\text { ( } n=3068)\end{array}$ & $\begin{array}{l}\text { Severe } \\
\text { dysfunction } \\
\text { ( } \mathrm{n}=4855)\end{array}$ & $\begin{array}{l}\text { Moderate } \\
\text { dysfunction } \\
(n=2050)\end{array}$ & $\begin{array}{l}\text { Normal/ } \\
\text { minimally } \\
\text { impaired } \\
\text { ( } n=4523)\end{array}$ \\
\hline \multicolumn{10}{|l|}{ Demographic characteristics } \\
\hline Age (median, years) & 79.0 & 74.9 & $59.7^{* *}$ & 80.1 & 74.9 & $58.6^{* *}$ & 78.3 & 75.0 & $60.5^{* *}$ \\
\hline Age $\geqslant 65$ years (\%) & 85.6 & 85.3 & $33.9 \dagger$ & 87.0 & 85.2 & $30.5 \dagger$ & 84.7 & 85.4 & $36.2 \dagger$ \\
\hline Male sex $(\%)$ & 40.8 & 51.3 & $78.2^{* *}$ & 36.5 & 54.7 & $83.1^{* *}$ & 43.5 & 49.0 & 74.9 ** \\
\hline \multicolumn{10}{|l|}{ Medical history (\%) } \\
\hline Diabetes & 32.0 & 26.8 & $21.8^{* *}$ & 28.5 & 27.1 & $19.8^{* *}$ & 34.2 & 26.7 & $23.2^{* *}$ \\
\hline Myocardial infarction & 40.4 & 35.6 & $28.5^{* *}$ & 37.0 & 29.4 & $20.7^{* *}$ & 42.4 & 39.6 & $33.8^{*}$ \\
\hline Heart failure & 28.8 & 16.3 & $5.7^{* *}$ & 26.4 & 15.2 & $4.6 * *$ & 30.4 & 17.0 & $6.4^{* *}$ \\
\hline Hypertension & 75.8 & 65.7 & $54.4^{\star *}$ & 70.0 & 62.3 & $47.3^{* *}$ & 79.3 & 68.0 & $59.2^{\star *}$ \\
\hline Peripheral vascular disease & 22.8 & 14.1 & $8.4^{\star \star}$ & 18.7 & 13.1 & $6.6^{* *}$ & 25.4 & 14.7 & $9.6 * *$ \\
\hline Atrial fibrillation & 14.6 & 12.5 & 5.1 ** & 14.4 & 11.6 & $3.3^{* *}$ & 14.6 & 13.1 & $6.4^{* *}$ \\
\hline TIA/stroke & 15.9 & 11.1 & $5.6 * *$ & 16.1 & 10.5 & $4.4^{* *}$ & 15.7 & 11.4 & $6.4^{* *}$ \\
\hline Current smoker & 9.0 & 13.9 & $34.2^{\star *}$ & 11.0 & 16.8 & $44.1^{* *}$ & 7.8 & 12.1 & $27.5^{\star *}$ \\
\hline CABG & 14.4 & 15.4 & $11.6^{* *}$ & 9.4 & 10.5 & $6.6^{* *}$ & 17.4 & 18.6 & $15.0^{*}$ \\
\hline $\mathrm{PCl}$ & 12.6 & 14.4 & $15.7^{*}$ & 9.4 & 8.8 & 9.1 & 14.5 & 18.0 & $20.1^{*}$ \\
\hline \multicolumn{10}{|l|}{ Presentation } \\
\hline $\begin{array}{l}\text { Time from symptom onset to } \\
\text { admission (median, min) }\end{array}$ & 210 & 180 & $165^{* *}$ & 196 & 165 & 140 ** & 215 & 200 & 188 \\
\hline $\begin{array}{l}\text { ECG changes }(\%) \\
\text { Killip class } \ddagger(\%)\end{array}$ & 76.2 & 72.0 & $70.7^{*}$ & 82.1 & 86.0 & $94.7^{* *}$ & 72.6 & 62.8 & $54.5^{* *}$ \\
\hline I & 64.3 & 75.0 & 89.2 & 60.2 & 71.1 & 86.9 & 66.8 & 77.6 & 90.8 \\
\hline$\|$ & 25.0 & 19.9 & 9.1 & 26.1 & 22.1 & 10.8 & 24.3 & 18.4 & 8.0 \\
\hline III & 10.8 & 5.1 & 1.7 & 13.7 & 6.8 & 2.3 & 8.9 & 4.0 & 1.3 \\
\hline
\end{tabular}

Severe renal dysfunction: creatinine clearance $(C C)<30 \mathrm{ml} / \mathrm{min}$; moderate renal dysfunction: CC 30-60 ml/min; normal/minimally impaired renal function: CC $>60 \mathrm{ml} / \mathrm{min}$.

${ }^{*} p<0.05$ across all categories of renal function within acute coronary syndromes (ACS), ST segment elevation myocardial infarction (STEMII), or non-ST segment elevation myocardial infarction/unstable angina (NSTEMI/UA) subgroups; ** $p<0.0001$ across all categories of renal function within ACS,

STEMI, or NSTEMI/UA subgroups; $\uparrow<<0.0001$ across all age groups and categories of renal function within ACS, STEMI, and NSTEMI/UA subgroups; $\ddagger p<0.0001$ across all Killip classes and categories of renal function within ACS, STEMI, and NSTEMI/UA subgroups.

$\mathrm{CABG}$, coronary artery bypass grafting; $\mathrm{PCl}$, percutaneous coronary intervention; TIA, transient ischaemic attack.

shown to differ from those enrolled in clinical trials. Therefore, clinical data that are less biased than those from randomised clinical trials, such as those presented here from GRACE, are important to complement the findings from large scale clinical trials that may underrepresent some important subgroups of patients. These include the elderly, women, and patients with varying degrees of renal dysfunction.

The results of our large descriptive study show greatly increased hospital death rates and risk of major bleeding episodes in patients with moderate or severe renal dysfunction in

Table 2 Medication use and in-hospital interventions for the study population

\begin{tabular}{|c|c|c|c|c|c|c|c|c|c|}
\hline \multirow[b]{2}{*}{ Renal function } & \multicolumn{3}{|l|}{ ACS } & \multicolumn{3}{|l|}{ STEMI } & \multicolumn{3}{|l|}{ NSTEMI/UA } \\
\hline & $\begin{array}{l}\text { Severe } \\
\text { dysfunction } \\
(n=786)\end{array}$ & $\begin{array}{l}\text { Moderate } \\
\text { dysfunction } \\
(n=3397)\end{array}$ & $\begin{array}{l}\text { Normal/ } \\
\text { minimally } \\
\text { impaired } \\
(n=7591)\end{array}$ & $\begin{array}{l}\text { Severe } \\
\text { dysfunction } \\
(n=301)\end{array}$ & $\begin{array}{l}\text { Moderate } \\
\text { dysfunction } \\
(n=1347)\end{array}$ & $\begin{array}{l}\text { Normal/ } \\
\text { minimally } \\
\text { impaired } \\
(n=3068)\end{array}$ & $\begin{array}{l}\text { Severe } \\
\text { dysfunction } \\
\text { ( } n=485)\end{array}$ & $\begin{array}{l}\text { Moderate } \\
\text { dysfunction } \\
(n=2050)\end{array}$ & $\begin{array}{l}\text { Normal/ } \\
\text { minimally } \\
\text { impaired } \\
(n=4523)\end{array}$ \\
\hline \multicolumn{10}{|c|}{ Medications before admission (\%) } \\
\hline Aspirin, & 46.8 & 47.1 & 39.6 ** & 38.0 & 34.6 & $24.4^{* *}$ & 52.3 & 55.3 & $50.0^{*}$ \\
\hline Ticlopidine/clopidogrel & 5.2 & 4.4 & $3.1^{*}$ & 4.4 & 2.7 & $1.8^{*}$ & 5.6 & 5.5 & $4.1^{*}$ \\
\hline ACE inhibitors & 34.3 & 32.4 & $22.3^{* *}$ & 32.6 & 28.9 & $16.7 * *$ & 35.4 & 34.8 & 26.2 ** \\
\hline ARBs & 5.9 & 3.6 & $2.4^{* *}$ & 4.1 & 2.6 & 2.1 & 7.0 & 4.2 & 2.6 ** \\
\hline$\beta$ Blockers & 34.5 & 31.8 & $29.0 *$ & 27.4 & 23.1 & 18.1 ** & 38.9 & 37.6 & 36.4 \\
\hline Diuretics & 38.4 & 25.4 & 11.9 ** & 37.0 & 21.7 & $8.6 * *$ & 39.3 & 27.9 & $14.2^{* *}$ \\
\hline Statins & 19.5 & 20.9 & 21.8 & 14.3 & 16.0 & 13.7 & 22.7 & 24.2 & $27.3^{*}$ \\
\hline \multicolumn{10}{|l|}{ In-hospital medications (\%) } \\
\hline Aspirin & 91.1 & 92.0 & $94.0 * *$ & 92.7 & 93.0 & $95.3^{*}$ & 90.1 & 91.3 & $93.1^{*}$ \\
\hline Ticlopidine/clopidogrel & 23.9 & 29.0 & $36.3^{* *}$ & 27.4 & 32.6 & $42.7^{* *}$ & 21.8 & 26.6 & 32.0 ** \\
\hline ACE inhibitors & 55.7 & 61.6 & $55.7^{* *}$ & 62.1 & 69.3 & $65.6 *$ & 51.8 & 56.4 & 49.0 ** \\
\hline ARBs & 6.4 & 3.8 & $2.5^{* *}$ & 3.8 & 2.9 & 2.3 & 8.0 & 4.4 & $2.6 * *$ \\
\hline$\beta$ Blockers & 69.3 & 74.3 & 83.8 ** & 64.9 & 73.8 & $86.2^{* *}$ & 72.0 & 74.6 & $82.2^{* *}$ \\
\hline Diuretics & 61.6 & 47.0 & $25.2^{* *}$ & 62.0 & 50.8 & $25.5^{* *}$ & 61.3 & 44.6 & 25.0 ** \\
\hline Statins & 33.4 & 42.0 & $53.3^{* *}$ & 31.6 & 41.1 & $54.3^{* *}$ & 34.5 & 42.7 & $52.6^{* *}$ \\
\hline LMWH & 46.7 & 49.4 & 50.1 & 47.3 & 46.6 & 45.7 & 46.4 & 51.2 & $53.1^{*}$ \\
\hline Thrombolytics & 7.2 & 13.3 & $19.5^{\text {** }}$ & 15.0 & 30.1 & $44.4^{* *}$ & 2.3 & 2.3 & 2.7 \\
\hline $\begin{array}{l}\text { GP Ilb/IIla } \\
\text { In-hospital interventions }\end{array}$ & 11.3 & 16.0 & $22.0^{* *}$ & 14.6 & 20.6 & $28.1^{* *}$ & 9.3 & 13.0 & $17.9^{* *}$ \\
\hline $\mathrm{PCl}$ or $\mathrm{CABG}$ & 22.6 & 30.3 & 39.8 * * & 27.3 & 36.4 & 47.1 * * & 19.7 & 26.3 & $34.8 * *$ \\
\hline
\end{tabular}

${ }^{*}$ * $\mathrm{p}<0.05$ across all categories of renal function within ACS, STEMI, or NSTEMI/UA subgroups; * $\mathrm{p}<0.0001$ across all categories of renal function within ACS, STEMI, or NSTEMI/UA subgroups.

$A C E$, angiotensin converting enzyme; ARB, angiotensin receptor blocker; GP, glycoprotein; LMWH, low molecular weight heparin. 


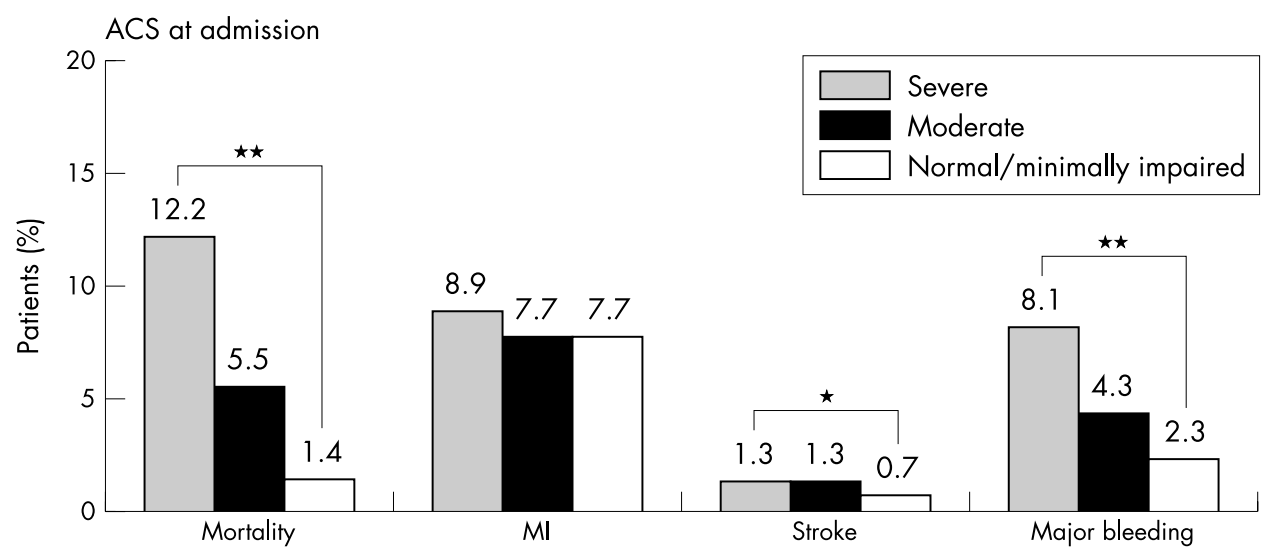

Figure 1 Hospital outcomes for all study patients with a diagnosis of acute coronary syndromes (ACS) at admission and for the subgroup of patients with ST segment elevation myocardial infarction (STEMI) and non-ST segment elevation myocardial infarction/unstable angina (NSTEMI/UA). * $p<0.05$ across all categories of renal function within ACS, STEMI, and NSTEMI/UA subgroups; ** $p<0.0001$ across all categories of renal function within ACS, STEMI, and NSTEMI/UA subgroups.
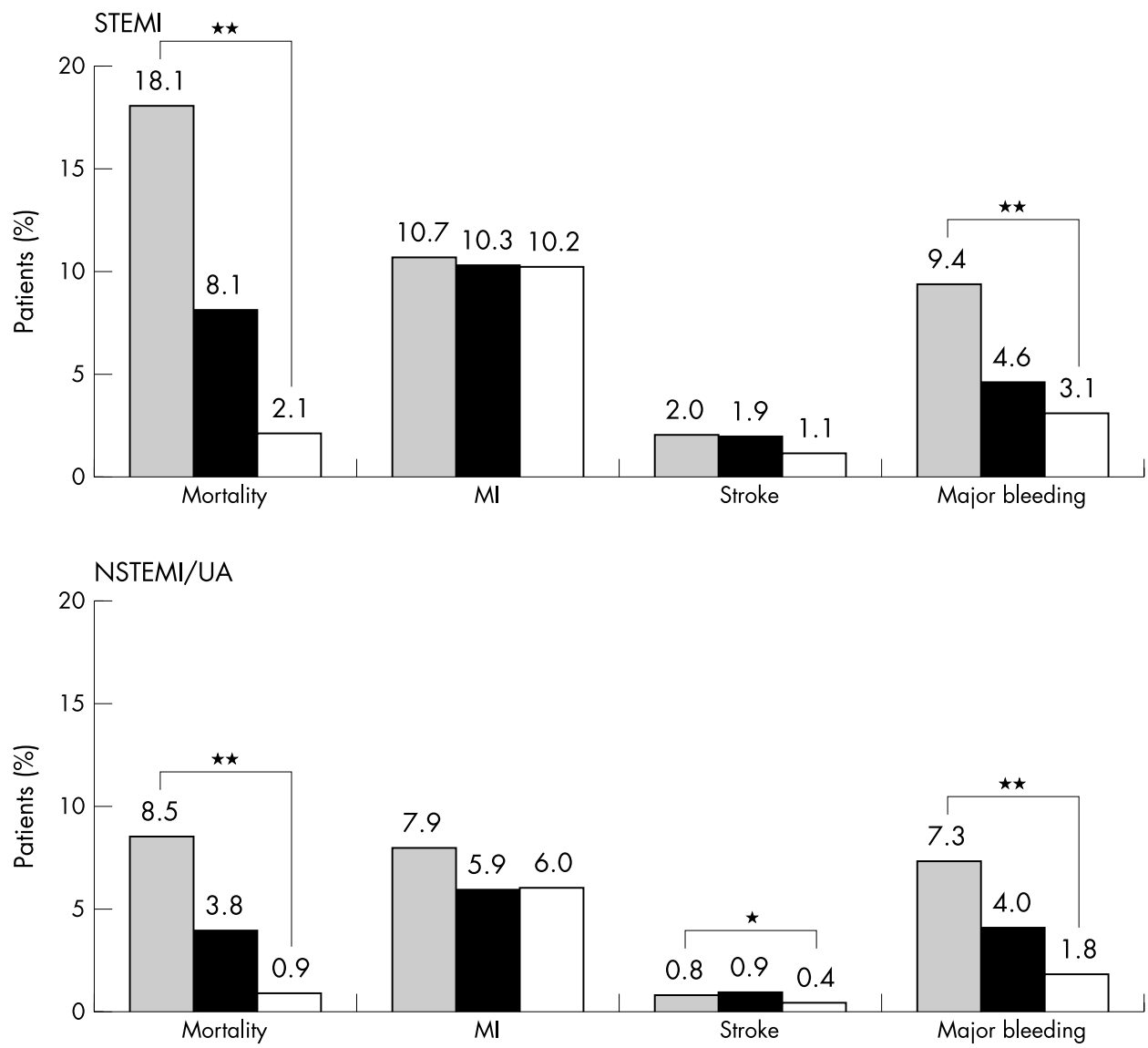

comparison with patients with normal renal function. We have shown that, in patients admitted with ACS and across each ACS grouping, creatinine clearance is an important independent predictor of hospital mortality and major bleeding. A $10 \mathrm{ml} / \mathrm{min}$ decrease in creatinine clearance had the same adverse impact on hospital death rates as a 10 year increase in age.
Increased renal dysfunction was observed more often in elderly (aged $\geqslant 65$ years) and female patients. It is well known that renal function decreases with age, and women are considerably older than men when they are admitted with an ACS, which may partially explain the predominance of women with reduced renal function. ${ }^{17}$

In an analysis of data from the TRACE (trandolapril cardiac evaluation) registry, ${ }^{17}$ the prognostic role of renal dysfunction

Table 3 Odds ratios (OR) for in-hospital outcomes for the study population

\begin{tabular}{|c|c|c|c|}
\hline Outcome & $\begin{array}{l}\text { Creatinine clearance* } \\
\text { (ml/min) }\end{array}$ & Crude OR $(95 \% \mathrm{Cl})$ & Adjusted OR $(95 \% \mathrm{Cl})$ \\
\hline \multirow[t]{2}{*}{ Death } & $<30$ & 9.92 (7.43 to 13.24$)$ & 3.71 (2.57 to 5.37$)$ \\
\hline & $30-60$ & $4.17(3.27$ to 5.32$)$ & $2.09(1.55$ to 2.81$)$ \\
\hline \multirow[t]{2}{*}{ Stroke } & $<30$ & 1.94 (0.98 to 3.84$)$ & $1.21(0.56$ to 2.60$)$ \\
\hline & $30-60$ & $2.03(1.35$ to 3.04$)$ & $1.42(0.87$ to 2.32$)$ \\
\hline \multirow[t]{2}{*}{ Major bleeding } & $<30$ & 3.70 (2.74 to 4.98$)$ & 2.78 (1.96 to 3.94$)$ \\
\hline & $30-60$ & 1.87 (1.49 to 2.34$)$ & 1.52 (1.17 to 1.99 ) \\
\hline
\end{tabular}


on mortality in more than 6000 patients with acute myocardial infarction was examined over a six year follow up. The unadjusted risk ratio associated with a calculated creatinine clearance $<40 \mathrm{ml} / \mathrm{min}$ compared with $>85 \mathrm{ml} /$ min was 7.1 (95\% confidence interval (CI) 6.2 to 8.0 ); for a creatinine clearance between 41 and $55 \mathrm{ml} / \mathrm{min}$, the odds of dying were 3.7 (95\% CI 3.3 to 4.2 ). However, after adjustment for other confounding variables, these risks were greatly attenuated to 1.4 and 1.1, respectively. The investigators concluded that only severely reduced renal function was associated with increased mortality after acute myocardial infarction, and the risk associated with moderate renal dysfunction may be explained by the presence of other comorbidities. These results differ from the findings of the present investigation. This may be partially attributed to the fact that we examined the relation of creatinine clearance to in-hospital mortality, whereas data from the TRACE registry were analysed over a six year period of follow up. Different pathophysiological mechanisms may play a part in explaining these discrepant results. These include accelerated atherosclerosis and a greater prevalence of comorbidities acting over a longer period of time. The GRACE findings are in agreement with the results of an earlier study ${ }^{18}$ of 2763 patients, in which renal insufficiency was an independent risk factor for cardiovascular events in patients with known coronary artery disease. Furthermore, Fried and colleagues, ${ }^{19}$ using data from nearly 6000 patients in the cardiovascular health study, reported recently that increased creatinine concentrations are common in older patients and are independently associated with an increased risk of death, cardiovascular disease, and congestive heart failure. Of interest was the finding that the increased risk of death began at low concentrations of creatinine.

Before hospital admission, patients with renal dysfunction in our study were treated with drugs of proven efficacy in the prevention of progression of renal and atherosclerotic disease. During acute hospitalisation, however, patients with moderate or severe renal dysfunction were less likely to receive interventions known to improve outcomes during hospitalisation for ACS. These treatments include $\beta$ blockers, antiplatelet agents, statins, glycoprotein IIb/IIIa inhibitors, thrombolytic treatment, and coronary interventional procedures. Diuretics were more often prescribed to patients with renal dysfunction across all ACS types and ACE inhibitors were prescribed more frequently to patients with a moderate degree of renal dysfunction, particularly in the subgroup of patients with STEMI. These findings are in agreement with the observations of several recent investigations in this area. ${ }^{18} 2021$

In both the STEMI and NSTEMI/UA groups, patients with renal dysfunction were more likely to have significant comorbidities and to have undergone coronary artery bypass surgery than other comparison groups. These findings are consistent with other published studies. ${ }^{22}$ However, there are very little data examining the use of coronary revascularisation procedures in patients with renal dysfunction, primarily because these patients have been excluded from clinical trials or have not been studied as specific subgroups. In GRACE, revascularisation procedures (percutaneous coronary intervention or coronary artery bypass grafting) were performed less frequently as renal dysfunction worsened within each diagnostic subgroup.

The risk of an acute stroke in patients with moderate and severe renal impairment tended to increase with worsening renal dysfunction. These findings are consistent with data from several other studies that showed associations of moderate renal dysfunction with stroke or transient ischaemic attack. ${ }^{1823}$ Major bleeding was observed more often within each diagnostic subgroup as renal dysfunction worsened. These findings are probably a result of decreased platelet function, which is commonly observed in patients with renal dysfunction. $^{12}$

\section{Strengths and limitations}

GRACE is the largest multinational observational study to include patients with the complete spectrum of ACS. The GRACE registry employs standardised criteria for defining ACS and hospital outcomes, and quality control and audit measures. One of the limitations of GRACE is its nonrandomised observational nature, and multivariate analysis was used in an attempt to reduce the bias inherent in this type of study. Creatinine clearance was estimated from creatinine measurements and was not measured directly.

\section{Conclusions}

Our data suggest that moderate renal insufficiency is an important independent predictor of hospital mortality and major bleeding episodes in patients admitted with any ACS diagnosis. For all patients admitted with ACS, there was also a trend towards a higher rate of occurrence of in-hospital strokes in patients with impaired renal function. Fewer effective cardiac treatment strategies that have been shown to improve outcomes in patients with ACS are applied to patients with impaired renal function, which may partially explain their worse hospital outcomes compared with patients with normal renal function. The measurement of renal function may provide an additional and important tool for risk stratification in patients presenting with ACS.

\section{ACKNOWLEDGEMENTS}

Funding and sponsorship for the GRACE study are provided by Aventis Pharmaceuticals (Bridgewater, New Jersey, USA). A steering committee and a publication committee were established from within the Scientific Advisory Committee. These committees oversee acquisition, analysis and publication of the data in an independent manner. Data are entered into the database by Premier Research, Philadelphia, Pennsylvania, and are stored and analysed at the Center for Outcomes Research of the University of Massachusetts Medical School, Worcester, Massachusetts. The authors had unrestricted access to the data in the preparation of this manuscript.

\section{APPENDIX}

GRACE Scientific Advisory Committee: Keith A A Fox, The Royal Infirmary of Edinburgh, Edinburgh, Scotland, UK; Joel M Gore, University of Massachusetts Medical School, Worcester, Massachusetts, USA. GRACE Co-Chairs: Kim A Eagle, University Hospital, Ann Arbor, Michigan, USA; Ph Gabriel Steg, Hôpital Bichat, Paris, France. GRACE Publication Committee Co-Chairs: Giancarlo Agnelli, University of Perugia, Perugia, Italy; Frederick A Anderson Jr, University of Massachusetts Medical School, Worcester, Massachusetts, USA; Álvaro Avezum, CTI-A Hospital Albert Einstein, São Paulo, Brazil; David Brieger, Concord Hospital, Sydney, Australia; Andrzej Budaj, Grochowski Hospital, Warsaw, Poland; Marcus D Flather, Royal Brompton \& Harefield NHS Trust, London, UK; Robert J Goldberg, University of Massachusetts Medical School, Worcester, Massachusetts, USA; Shaun G Goodman, St Michael's Hospital, Toronto, Ontario, Canada; Christopher B Granger, Duke University Medical Center, Durham, North Carolina, USA; Dietrich C Gulba, Cardiology Krankenhaus Düren Medizinische Klinik, Düren, Germany; Enrique P Gurfinkel, Buenos Aires University, Buenos Aires, Argentina; Brian M Kennelly, Hoag Memorial Hospital Presbyterian, Newport Beach, California, USA; Werner Klein, Medizinische Universitätsklinik, Graz, Austria; José López-Sendón, Hospital Universitario Gregorio Marañon, Madrid, Spain; Gilles Montalescot, Pitié-Salpétrière Hospital, Paris, France; Frans Van de Werf, University of Leuven, Leuven, Belgium.

\section{Authors' affiliations}

J J Santopinto, G Piñero, Intensive Care Unit, Leonidas Lucero's Hospital, Bahia Blanca, Argentina

K A A Fox, The Royal Infirmary of Edinburgh, Edinburgh, UK R J Goldberg, J Esteban, J M Gore, J Johnson, University of Massachusetts Medical School, Worcester, Massachusetts, USA A Budai, Grochowsky Hospital, Warsaw, Poland A Avezum, CTI-A Hospital Albert Einstein, São Paulo, Brazil D Gulba, Krankenhaus Düren Medizinische Klinik, Düren, Germany E P Gurfinkel, Favaloro University, Buenos Aires, Argentina 


\section{REFERENCES}

1 Wannamethee SG, Shaper AG, Perry IJ. Serum creatinine concentration and risk of cardiovascular disease: A possible marker for increased risk of stroke. Stroke 1997;28:557-63.

2 Alcorn HG, Wolfson SK Jr, Sutton-Tyrrell K, et al. Risk factors for abdominal aortic aneurysms in older adults enrolled in the cardiovascular health study. Arterioscler Thromb Vasc Biol 1996:16:963-70.

3 Gottlieb SS, Mc Carter RJ, Vogel RA. Effect of beta-blockade on mortality among high risk and low risk patients after myocardial infarction. N Engl J Med 1998:339:489-97.

4 Pahor M, Shorr RI, Somes GW, et al. Diuretic-based treatment and cardiovascular events in patients with mild renal dysfunction enrolled in the systolic hypertension in the elderly program. Arch Intern Med 1998; 158:1340-5

5 Culleton BF, Larson MG, Wilson PW, et al. Cardiovascular disease and mortality in a community-based cohort with mild renal insufficiency. Kidney Int 1999:56:2214-9.

6 Landray MJ, Thambyrajah J, McGlynn FJ, et al. Epidemiological evaluation of known and suspected cardiovascular risk factors in chronic renal impairment. Am J Kidney Dis 2001;38:537-46.

7 Cerne D, Kaplan-Pavlovcic S, Kranjec I, et al. Mildly elevated serum creatinine concentration correlates with the extent of coronary atherosclerosis. Ren Fail 2000;22:799-808.

8 Culleton BF, Larson MG, Evans JC, et al. Prevalence and correlates of elevated serum creatinine levels: the Framingham heart study. Arch Intern Med 1999:159:1785-90.

9 Eagle KA, Goodman SG, Avezum A, et al. Practice variation and missed opportunities for reperfusion in ST-segment-elevation myocardial infarction: findings from the global registry of acute coronary events (grace). Lancet 2002;359:373-7.

10 Anon. Rationale and design of the GRACE (global registry of acute coronary events) project: A multinational registry of patients hospitalized with acute coronary syndromes. Am Heart J 2001;141:190-9.

11 Steg PG, Goldberg RJ, Gore JM, et al. Baseline characteristics, management practices, and in-hospital outcomes of patients hospitalized with acute coronary syndromes in the global registry of acute coronary events (GRACE). Am J Cardiol 2002;90:358-63
12 Levey AS. Controlling the epidemic of cardiovascular disease in chronic renal disease: where do we start? Am J Kidney Dis 1998;32:S5-13.

13 Ruilope LM, van Veldhuisen DJ, Ritz E, et al. Renal function: the cinderella of cardiovascular risk profile. J Am Coll Cardiol 2001;38:1782-7.

14 Cockcroft DW, Gault MH. Prediction of creatinine clearance from serum creatinine. Nephron 1976;16:31-41.

15 Levey AS, Bosch JP, Lewis JB, et al. A more accurate method to estimate glomerular filtration rate from serum creatinine: a new prediction equation. Modification of diet in renal disease study group. Ann Intern Med 1999;130:461-70.

16 Granger CB, Goldberg RJ, Dabbous OM, et al. Predictors of hospital mortality in the global registry of acute coronary events [in press]. Arch Intern Med 2003

17 Sorensen CR, Brendorp B, Rask-Madsen C, et al. The prognostic importance of creatinine clearance after acute myocardial infarction. Eur Heart J 2002;23:948-52.

18 Shlipak MG, Simon JA, Grady D, et al. Renal insufficiency and cardiovascular events in postmenopausal women with coronary heart disease. J Am Coll Cardiol 2001;38:705-11

19 Fried LF, Shlipak MG, Crump C, et al. Renal insufficiency as a predictor of cardiovascular outcomes and mortality in elderly individuals. J Am Coll Cardiol 2003;41:1364-72.

20 Shlipak MG, Heidenreich PA, Noguchi $H$, et al. Association of renal insufficiency with treatment and outcomes after myocardial infarction in elderly patients. Ann Intern Med 2002;137:555-62.

21 Wright RS, Reeder GS, Herzog CA, et al. Acute myocardial infarction and renal dysfunction: a high-risk combination. Ann Intern Med 2002;137:563-70

22 Aronow WS, Ahn C, Mercando AD, et al. Prevalence of coronary artery disease, complex ventricular arrhythmias, and silent myocardial ischemia and incidence of new coronary events in older persons with chronic renal insufficiency and with normal renal function. Am J Cardiol 2000;86:1142-3, A9.

23 Manolio TA, Kronmal RA, Burke GL, et al. Short-term predictors of incident stroke in older adults. The cardiovascular health study. Stroke 1996;27:1479-86.

\section{FROM BM JOURNALS}

\section{Observational study of prehospital delays in patients with chest pain T Hitchcock, F Rossouw, D McCoubrie and S Meek}

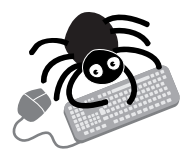

Please visit the Heart website [www.heartinl. com] for link to this full article.
Objective: To define and measure patient reported prehospital delay in presentation to the emergency department with chest pain and identify simple strategies that may reduce this delay. The authors investigated the null hypothesis that the patient's choice of service to call for acute medical help has no effect on the timing of thrombolysis.

Method: A prospective observational study of prehospital times and events was undertaken on a target population of patients presenting with acute chest pain attributable to an acute coronary syndrome over a three month period.

Results: Patients who decided to call the ambulance service were compared with patients who contacted any other service. Most patients who contact non-ambulance services are seen by general practitioners. The prehospital system time for 121 patients who chose to call the ambulance service first was significantly shorter than for 96 patients who chose to call another service (median $57 \mathrm{~min}$ v $107 \mathrm{~min}$; $<<0.001$ ). Of the 42 patients thrombolysed in the emergency department, those who chose to call the ambulance service had significantly shorter prehospital system times (number 21 v 21 ; median 44 v 69 min; $p<0.001$ ). Overall time from pain onset to initiation of thrombolysis was significantly longer in the group of patients who called a non-ambulance service first (median 130 min $v 248$ min; $p=0.005$ ). Conclusions: Patients with acute ischaemic chest pain who call their general practice instead of the ambulance service are likely to have delayed thrombolysis. This is likely to result in increased mortality. The most beneficial current approach is for general practices to divert all patients with possible ischaemic chest pain onset within 12 hours direct to the ambulance service.

\ Emerg Med J 2003; 20:270-273 